\title{
Bacia do Acre - integração dos dados sísmicos e métodos potenciais adquiridos pela ANP
}

Raphael Victor Aleixo Vasconcellos, ANP

Renato Lopes Silveira, ANP

José de Ribamar Lopes Bezerra, ANP

Ricardo Campos Alevato, UERJ

Gustavo Santana Barbosa, ANP

Copyright 2018, SBGf - Sociedade Brasileira de Geofísica

Este texto foi preparado para a apresentação no VIII Simpósio Brasileiro de Geofísica, Salinópolis, 18 a 20 de setembro de 2018. Seu conteúdo foi revisado pelo Comitế Técnico do VIII SimBGf, mas não necessariamente representa a opinião da SBGf ou de seus associados. É proibida a reprodução total ou parcial deste material para propósitos comerciais sem prévia autorização da SBGt.

\section{Resumo}

A Bacia do Acre é pouco estudada. O fato se dá por questões ambientais que impedem o aprofundamento do conhecimento geológico da bacia e assim, a avaliação de seus possíveis recursos energéticos. No entanto, a Agência Nacional do Petróleo, Gás Natural e Biocombustíveis (ANP) realizou uma série de atividades exploratórias que resultaram em um acervo de conhecimento geológico dessa bacia. Destacam-se em ordem cronológica, levantamentos aerogeofísicos que cobriram toda a Bacia do Acre e Madre de Dios em 2008, a aquisição de 2.040 amostras de solo em 2009 para realização de análises geoquímicas básicas das quais 90 foram selecionadas para análise detalhadas e um programa regional de levantamento sísmico. Em 2012 houve o processamento de dados sísmicos antigos (pré98) e em 2013, quando os dados sísmicos foram adquiridos perfazendo um total de $1000 \mathrm{Km}$ lineares de com metodologia 2D obteve-se também registros de gravimetria e magnetometria associados. Os dados de aerolevantamento mostraram baixos gravimétricos que poderiam indicar existência de possíveis grabens na Bacia do Acre, já em território do estado do Amazonas em uma região de mata fechada. Entretanto, o resultado da sísmica indicou que, na verdade, os possíveis baixos gravimétricos se tratavam apenas de diferença de densidade do embasamento que se refletiram nos dados de aerolevantamento.

\section{Introdução}

A Bacia do Acre está localizada na região amazônica, no extremo oeste do país em uma área de aproximadamente $97.000 \mathrm{~km}^{2}$ (Figura 1) e, apesar de sua área inóspita, foi investigada por onze poços. A Bacia do Acre é preenchida por sedimentos paleozoicos a cenozoicos com diversas discordâncias de caráter regional. Seu pacote sedimentar pode ser superior a 4.700 metros no depocentro da bacia, nas proximidades da região da falha de Batã. A bacia possui apenas onze poços, coinforme já citado perfurados em toda sua extensão, dos quais três apresentam indícios de hidrocarbonetos. No entanto, o ponto crítico do sistema petrolífero são as rochas geradoras que ainda não foram determinadas. Nesse intuito, a ANP obteve diversos dados na região da bacia, para o melhor entendimento da

sua compartimentação estrutural e imagear a distribuição das formações ao longo da mesma. Nos últimos 10 anos, os investimentos realizados pela ANP totalizam um valor da ordem de $R \$ 77$ milhões nas bacias do Acre e Madre de Dios, incluindo a execução de levantamentos aerogeofísico, geoquímico de superfície, aquisição sísmica bidimensional e processamento de linhas sísmicas antigas (pré-1998). Os dados de aerolevantamentos gravimétricos e magnetométricos permitem investigar a extensão dos sedimentos e estruturas profundas relacionadas ao embasamento da bacia. O levantamento geoquímico indicou ocorrência de microexsudações de origem termogênica, apontando para a ocorrência de sistema petrolífero ativo, com propensão para geração de gás natural. Os dados adquiridos por meio da aquisição sísmica apresentam elevada qualidade e permitiram identificar as principais sequências sedimentares e importantes feições estruturais em grande extensão na bacia, incluindo regiões nunca antes imageadas.

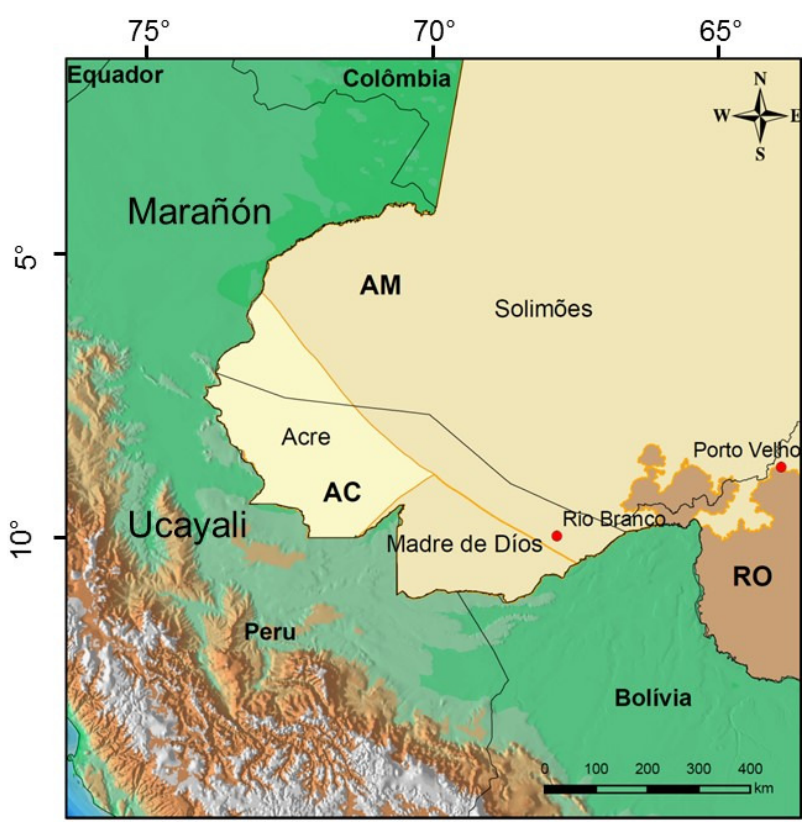

Figura 1 - Mapa de localização da Bacia do Acre.

\section{Metodologia}

A análise de dados sísmicos $2 \mathrm{D}$ discutidos neste trabalho se deu com a utilização do software Petrel® com amarração dos poços e utilização das curvas dos perfis elétricos obtidos na Bacia. Como comentado anteriormente, são apenas 11 poços. Para análises de 
dados gravimétrico e magnetométricos foi utilizado o software Geosoft@ para geração dos perfis gravimétricos e magnetométricos bem como mapas de anomalias que após gerados os grids foram transformados em formato .tiff para facilitar utilização, visualização e interpretação no $\operatorname{ArcGis}{ }^{\circledR}$ e integrar com outros dados adquiridos na região da Bacia do Acre. Vale destacar que todos os dados utilizados são públicos, ou devido ao tempo que foram adquiridos ou por terem sido adquiridos pela ANP.

\section{Resultados}

A aquisição dos dados de métodos potenciais ocorreu em 2008 e gerou grande expectativa na Bacia do Acre (Neves, 2008). Tais dados indicavam a existência de alguns baixos gravimétricos que poderiam ser grabens na região leste e sul da bacia. Também com esse trabalho foi possível relacionar uma descontinuidade do Arco de lquitos que separa a bacia do Acre com a Bacia do Solimões.

A análise dos dados gravimétricos (Figura 2) indicaram alguns baixos gravimétricos nas porções mais a leste e sul da Bacia do Acre, já adentrando o Estado do Amazonas. Entretanto os resultados obtidos com a análise dos dados sísmicos permitiram distinguir que se trata apenas de diferença de densidade do embasamento. Da mesma forma, o trabalho de aerolevantamento indicou altos gravimétricos e diferentes comportamentos no mapa magnetométrico apontaram heterogeneidades crustais e permitiram a identificação das principais feições do arcabouço estrutural da bacia.

Nos dados Magnetométricos (Figura 3), é possível identificar pelo menos dois compartimentos totalmente diferentes no quesito de susceptibilidade magnética, uma mais a oeste/noroeste da bacia e o segundo mais a sudeste da bacia.

A sísmica adquirida pela ANP em 2013 é de excelente qualidade, possui caráter regional e permitiu distinguir a compartimentação tectônica da Bacia do Acre, com zoneamento das áreas de interesse. A região mais profunda da bacia localiza-se entre as falhas de Batã e Oeste de Batã, podendo chegar a 4.700 metros de profundidade. Esse levantamento confirmou que o maior potencial exploratório se concentra em sua porção oeste, que apresenta uma dobra anticlinal relacionada à frente de empurrões gerada por esforços compressionais resultantes da colisão entre as Placas Sul-Americana e Nazca. A análise dos dados sísmicos adquiridos pela ANP permitem ainda perceber um razeamento da bacia para Leste e Sul da Bacia do Acre, com deposição de sedimentos do Cretáceo e Cenozóico nessa região, sendo possível ainda ver a discordâncias associadas ao diastrofismo Juruá. As feições associadas a este evento são pujantes entre as falhas de Batã e Batã Oeste.

Os dados gravimétricos e magnetométricos adquiridos simultaneamente com a sísmica 2D também indicaram tais feições (baixos gravimétricos).

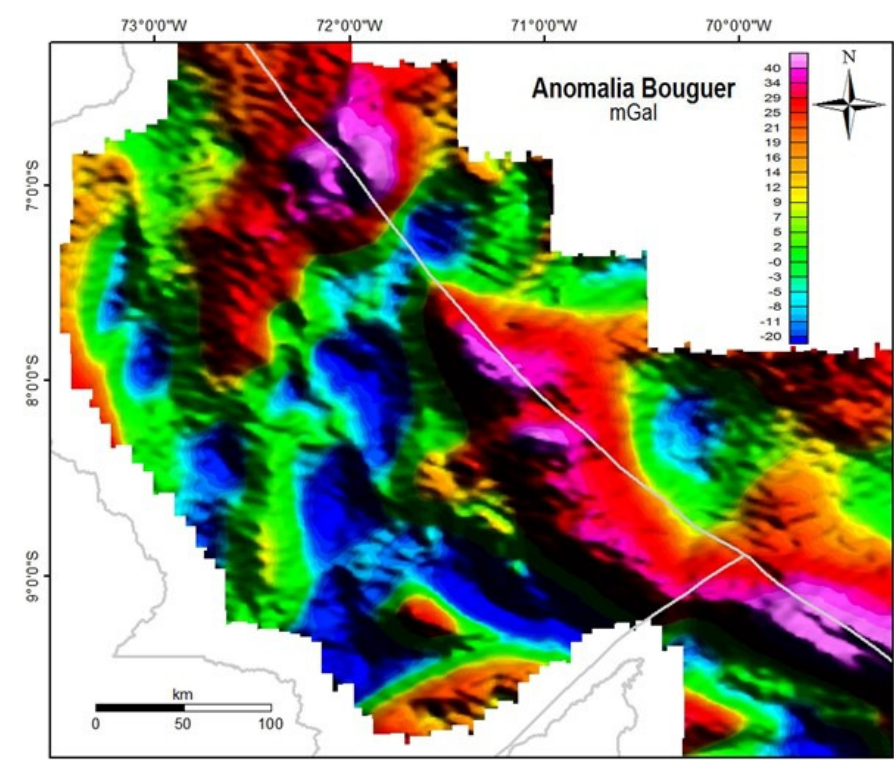

Figura 2 - Mapa de anomalia Bouguer, mostrando baixos gravimétricos que posteriormente foram investigados com a sísmica adquirida pela ANP.

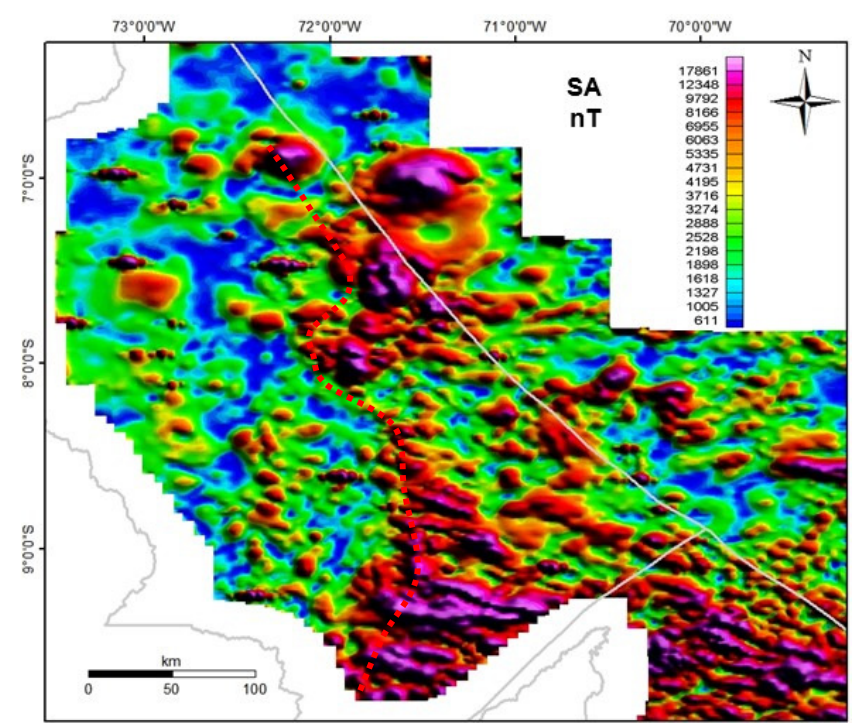

Figura 3 - Mapa magnetométrico, S.A. (Sinal Analítico) mostrando duas regiões distintas em termos de composição do envasamento. 


\section{Discussão e Conclusões}

A aquisição dos dados sísmicos e de métodos potenciais, bem como a aquisição de dados geoquímicos e o reprocessamento de dados antigos se torna de grande valia, pois a Bacia do Acre é carente de dados geológicos/geofíscos. Para se ter uma noção, o último poço foi perfurado em 1995 e são apenas 11 poços em seus $97.000 \mathrm{~km}^{2}$ de área. Vale destacar que se trata de uma bacia desconhecida para o Brasil e possui rochas análogas produzindo hidrocarbonetos em bacias peruanas e bolivianas, como Marañón, Ucayali e Madre de Dios.

Contudo, além da questão ambiental bastante sensível na região, continua sendo o maior desafio exploratório na bacia, o quesito geração do sistema petrolífero. Aventase a possibilidade de geração nos sedimentos permocarboníferos da Formação Cruzeiro do Sul, em analogia com os folhelhos geradores da Formação Copacabana e Ene, na Bacia de Ucayali (Peru). Outra alternativa se ampara em eventual geração proveniente de folhelhos devonianos, ainda não amostrados nesta área, mas inferidos por meio de interpretação de dados geoquímicos (Mello e Elias, 2009) e refletores sísmicos profundos, restritos entre as falhas de Batã e Oeste de Batã (Cunha, 2007; Oliveira, 1994 e Vasconcellos e Coutinho, 2013). As rochas reservatório são arenitos e carbonatos da Formação Cruzeiro do Sul, cujos folhelhos intraformacionais podem atuar também como selo.

Infelizmente, a aquisição dos dados sísmicos acabou confirmando a inexistência dos referidos grabens na região leste e sul da Bacia do Acre (Figuras 4 e 5), ficando evidente a existência de diferença de densidade intraembasamento e aparentemente há intensa movimentação neste embasamento. A Bacia do Acre é a única bacia brasileira que experimentou os esforços compressivos das orogenias andinas, permitindo a formação de trapas estruturais de grande porte, especialmente aquelas relacionadas às estruturas compressionais associadas às falhas de Batã e Oeste de Batã.

A referida configuração estrutural eleva a expectativa com relação ao potencial desta área, especialmente em razão da semelhança com bacias produtoras no Peru e na Bolívia. Por se localizar em região remota, a exploração na Bacia do Acre apresenta diversos desafios, contudo, sua proximidade e analogia a bacias produtoras de hidrocarbonetos peruanas e bolivianas incentivam a continuidade da investigação do potencial exploratório.

Hoje em dia para a continuidade dos estudos na bacia, seria bastante interessante a perfuração de um poço na região mais profunda da Bacia do Acre, mas precisamente na região entre as falhas de Batã e Oeste de Batã, a fim de amostrar possíveis rochas geradoras do Devoniano (Cunha,2007 e Elias, 2009).

\section{Agradecimentos}

Agradecimentos aos colegas da Superintendência de Exploração da ANP e as superintendências do Upstream da ANP que de alguma forma contribuíram para a realização do trabalho. Agradecemos ainda ao BDEP e ao laboratório Infodidática da UERJ.

\section{Referências}

CUNHA, P.R.C. Bacia do Acre. Boletim de Geociências da Petrobras, Rio de Janeiro V.15 n² 2 . Maio/Nov. P. 207215, 2007

DUARTE, K.S. Levantamento Exploratório da ANP na Bacia do Acre, in. http://www.bdep.gov.br/?id=501. 2011 MELLO, M.R. e ELIAS, V. 2009. Estudo de Geoquímica e microbiologia de superfície na bacia do Acre.Relatório final de Projeto ANP-HRT. Rio de Janeiro, $109 \mathrm{p}$.

OLIVEIRA, C. M. M. Estilos estruturais e evolução tectônica da Bacia do Acre. 1994. 206 p. il. Dissertação (Mestrado). Universidade Federal de Ouro Preto, Ouro Preto, Minas Gerais, 1994.

VASCONCELLOS, R. V. A. e COUTINHO, C. I. 2013 Bacia do Acre. $12^{\circ}$ Rodada de Licitações da ANP. 


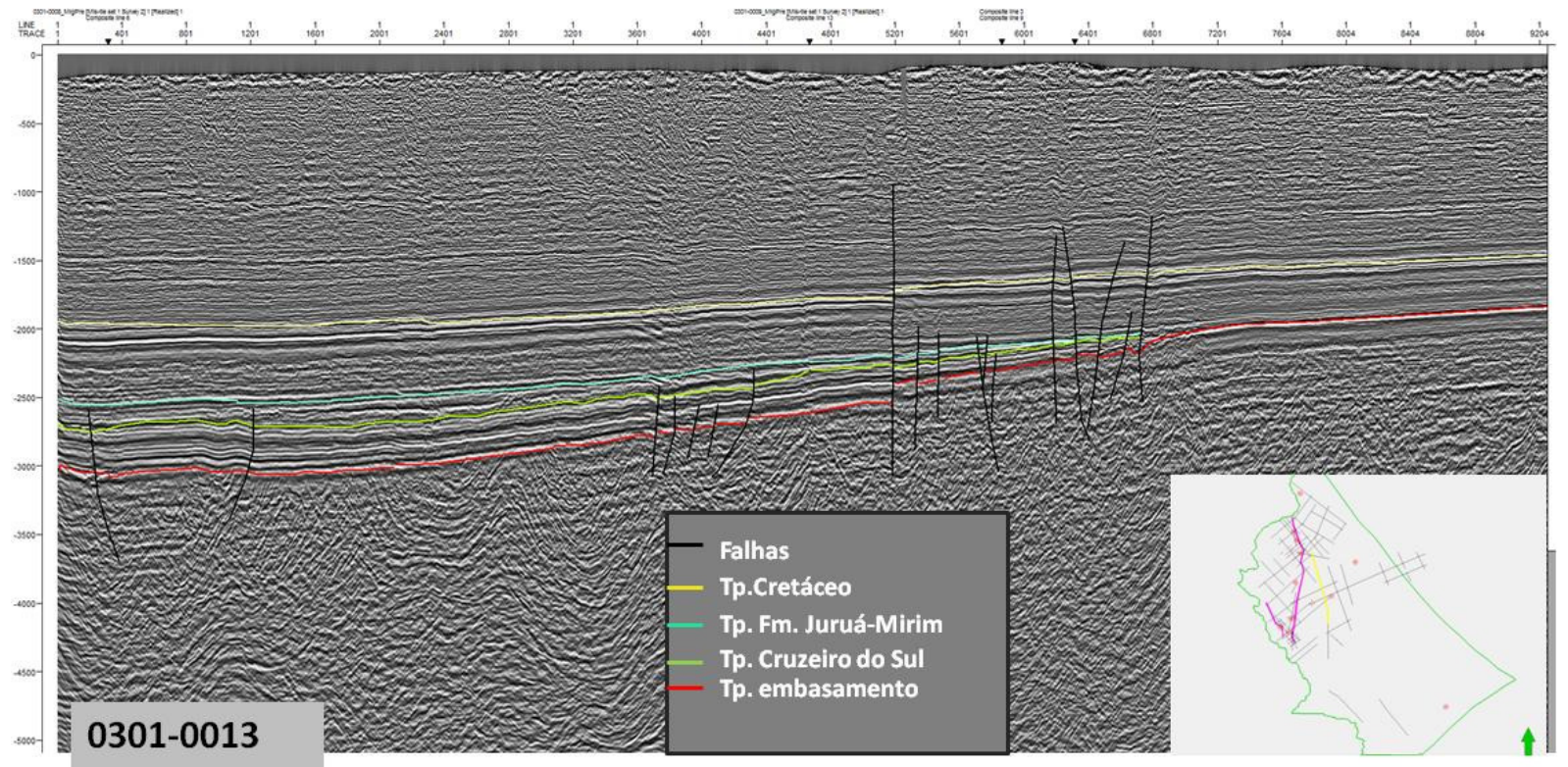

Figura 4 -Perfil Norte Sul mostrando razeamento da bacia.

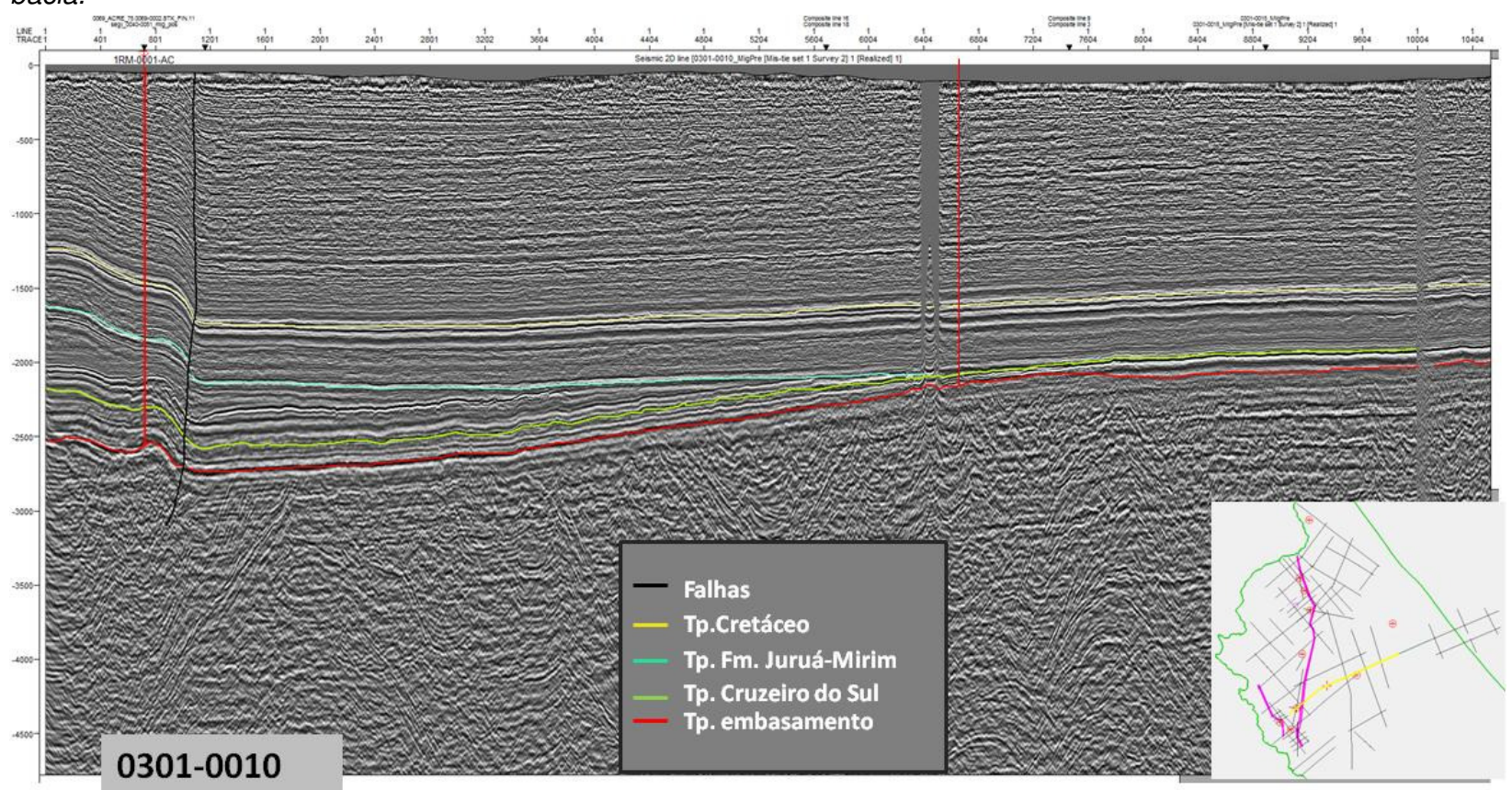

Figura 5 - Perfil Leste Oeste Mostrando razeamento da bacia e assim afasta a possibilidade de existência de grabens. 